\title{
中藥在科舄技術上存在的問題
}

\author{
㩟 之 岑
}

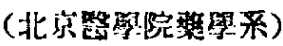

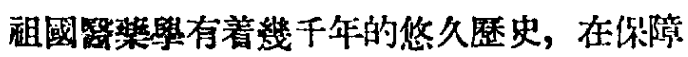

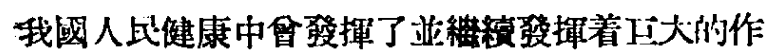

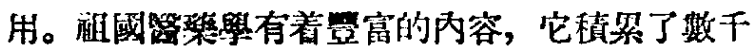

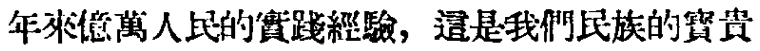

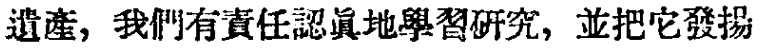
光大，使之成篇祖國科學對現代世界科學的脌大 貢龆的一部分。

過去，我們對中醫樂的重悓是十分不够的，

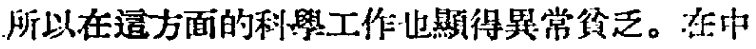
棨方面，踓會有人作過一些利學研究工作，但大 多數是零碎的、片段的、没有聯系的、没有系維 的，砳究的結果不能應用於實際，因此對中渻的 發展來講亚没有多大瑟趿。

在黨和人民政府的號召下，目前已經開始拝

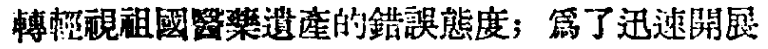
中然方面的工作，我想把中藥在利學技術上标在 的問題提出來和大家商討。

\section{一 目前急待解决的中藥供應問題}

幾年來，由於有關部門沒有重視中愁的生堂 與供應等問題,以致不少中樂供不㮣求,少數重要 中燕留於奇缺狀態。在中愁工作中，首先應該考 丠的是如何保證克分供應足够數量品質传度的中

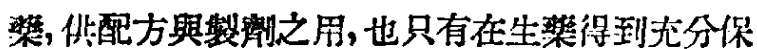
澄挠，予可以順利地進行廣泛的試驗研究工作。

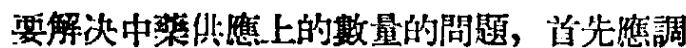
查常用中森種類及偕銷數字。有缺乏之庭的小浆，

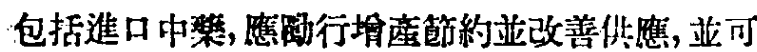

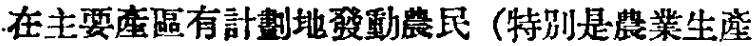
合作社)進行栽培, 由國家計劃收䁚:。野生䒚物的

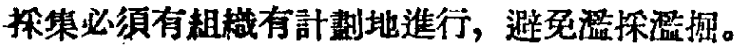

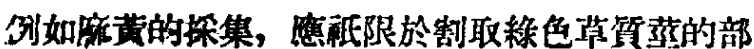

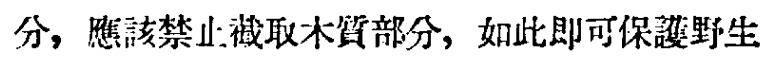
植物，不致因探集而減少。此外，對於探集時期、 乾焒方法等也須注意, 做到探集適時, 乾煤 迅 速, 以玿探集的整物品犋低少。

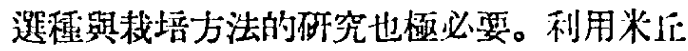
林與李椂科的工作方法，不但可使慗用植物的尘 量㘿加，而且可以提高品罂。尤其是對於些上缺之 裁培絕驗的野生植物和國外植物，國家仃以考䒔

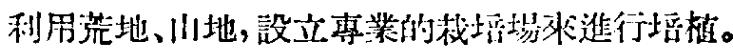

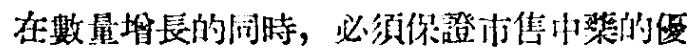

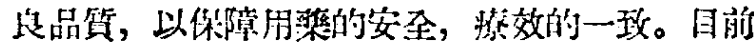

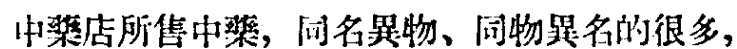

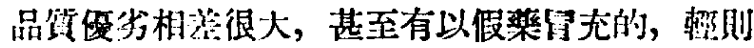

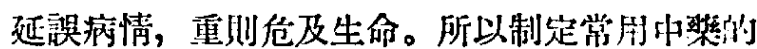

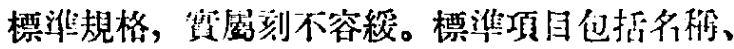

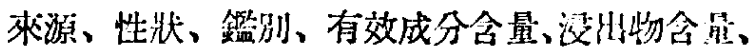

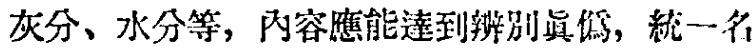

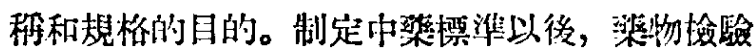

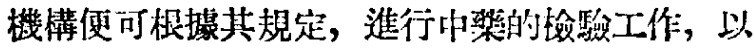

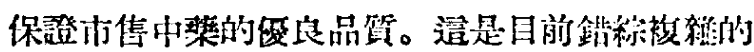
中樂問題的一個基本問题。做好追一项工作，不

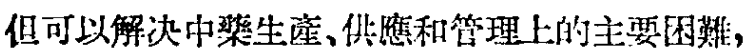
而且地可以雼今後的中架研究工作栠定基礎（閣

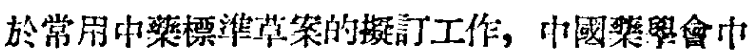
慗整理委員會已擬有方案)。

\section{二 中蓃的娪型改進和化瞍、 蓄理、臨床的研究工作}

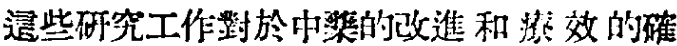
定，是不可缺少的绦件。但這些工作大多需要较 長的時間，而且各項研究工作相后間都有密切的 聯系，不能把它们完全孤立起来進行。今将管見 
所及, 分述如下:

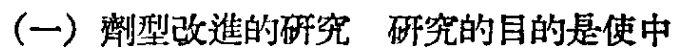
樂成篇更易於服用, 能更好地發揮療效, 而且便 於保存的形式。目前病人吃湯棐是一大碗, 吃丸 然是幾大顆，很以篇苦; 大量草樂，在運輸、携 帶和保存上也感不便。解型的改淮, 有其必要。 但淿型改進必須要和化學、樂理、臨床的研究相 配合，以炛改進了剂型，失去了療效。在追寡我 想指出, 有些人認黨未經改進的生菜煎劑是不科・ 學的, 這種看法是錯誤的。因临有許多藥效成分 在生藥狀熊可以保存得比任何其他形式都好。但

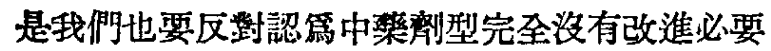
的保守思想。

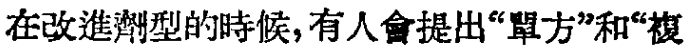
方”的問題。因篇中醫垦方很少用單味槊, 絕大多 數處方都是君臣佐使各采互相配合, 少則五六味, 多則百十味，或則慗丸，或則前湯內服，各樂之 間可以有“合奏”的功效。是否改淮劑型之後合奏 的功效會失去呢? 我想不會的。改進劑型可以從 兩方面着手: 一方面是就古方成䒚進行利型的改

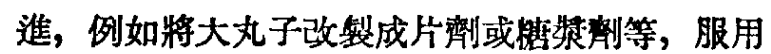
上就比較方便；另一方面是將單味整製成醇劑、

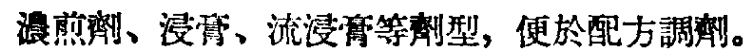
㷊店中只要將處方上各樂配合就成一瓶樂水，服 用時，仍可發生合奏作用，可是省去了臨時前樂 的䟽煩。

（二）化舉成分的研究 國內過去也畣有些

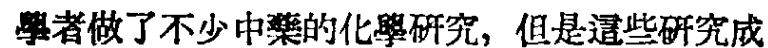
果, 很少能應用到賽際中去, 將中樂加以改進。 其中主要原因, 就是由於他們是從化學的觀點來 進行研究, 而不是以桨篹的觀點整進行研究的緣 故; 常常是把化學的研究孤立起來進行, 沒有能

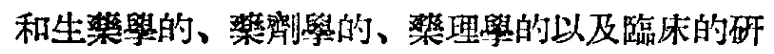

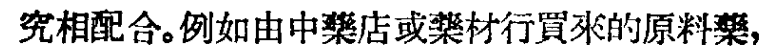
没有經過生祭學的鑑定，其真嵒侵劣就不明膫。 過去會有這樣的例子，即一位化學家去中樂店買 了一種中樂來進行分析，發現囬面含有多量生物 䠯，而揵另一位化學家研究同名中樂的結果，却 並不含生物襝, 這種研究結果的發表, 當然全引 起爭諭和誤會。迶主要不是由於技衕上有什㦄問 題，而是由於二人所買到的中藥是同名異物，結 果當然不會一樣。
中樂化學成分的研究，首先在於磪定有效成 分的性質，並設法將其分離。至於進一步探明其 化學構造，並設法合成，蓬至於改變其構造以合 成新的樂物等等, 㗬然也是化學研究的目標, 但 需要很長的時間，不是很快就可獲得結果的。

有效成分的性筫及其分雄方法的研究，是不 能脫離樂理試驗的。過去有人花了数年功夫分離 出來某種結晶, 並探求了它的化悬構造, 但是連 種結晶是否具有樂理作用却並不知道。道種研究 方式對中樂改進工作是很少慗助的。和樂理試䮑 密切結合的最好方式，是每做一步化學的分離操 作，就將已分教的各部分分别進行䣋理試驗，觀 察其作用究在何部分, 然後集中精力將該部分楼 絿精赀，並反復淮行樂理試驗，以求獲得純粹的 有效成分。近十幾年來抗生素研究之所以獲得極 大的成就, 就是由於化學研究和菜理試驗（生物 測定）密切配合的結果。當然, 造種配合在研究 某些中菜時，也是有困難的，例如有些中箱，其 效力不是很明㙷面高特的。因此, 不能用某一種 簡單的藥理試驗來决定分離出來的成分，是否代 表了生槊的全部療效。

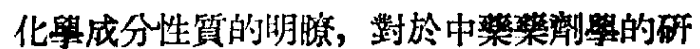

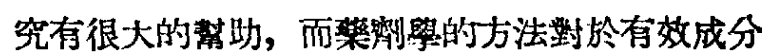
的研究也有很大的用處。例如將某樂的某一部分

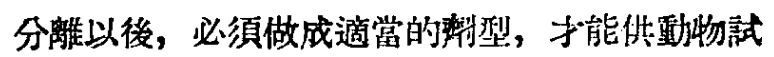
驗, 使楽理作用不受其他因素的影短而能充分顯 現出來。

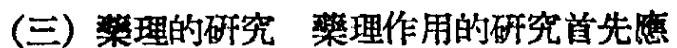
確定䒩物毒性的强弱, 以制定姃物的極量, 保障 病人的安全; 淮而研究其作用方式, 闹時虑用生 理化燢的方法, 確定楽物在體內變化的過程; 亚 淮一步設計生物测定的方法, 以便配合化罗的研

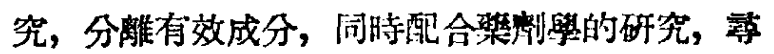
求更好的用祭方式。

有人認第樂理試驗好像一面策，把各種中辈 都拿來過一下篩, 可以確定㑚些䉾有用, 值得研 究, 那些楽没有用, 不值得研究。道種看法是有 問題的。如前所說，有許多中藥的作用不是很明

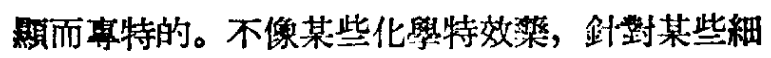

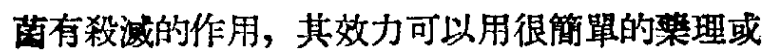
湅菌學的方法來測定。根據中醫的渔驗，有許多 〔下接 37 真〕 